\title{
Analysis of the Retrospective Self-Assessment Questionnaire of a Faculty Development Programme
}

\author{
Revathi M. ${ }^{1}$, Vijayalakshmi B. ${ }^{2}$, Navin Rajaratnam¹, Chandrasekar M. ${ }^{1}$
}

\begin{abstract}
Introduction: Faculty development programmes (FDP) provide an integral training opportunity to learn the art of teaching, learning and assessment. The effectiveness of a medical education workshop is frequently assessed by retrospective pre- evaluation self-assessment questionnaires. The objective of this study was to analyse the importance and skills perceived by the participants on various competencies gained as during the FDPs by retrospective pre-evaluation self-assessment rating questionnaire.
\end{abstract}

Methodology: In-house faculty $(n=62)$, from various clinical and nonclinical departments participated in the faculty development programme which was conducted Medical Education Unit, Meenakshi Medical College Hospital and Research Institute. At the end of the three days workshop, a retrospective prequestionnaire was used for self-rating of the individual session. The importance of the workshop and the skills learnt in relation to various competencies were self-rated by the individual participants.

Results: At the end of the workshop, 94\% of the participants self-rated the topics; 'Microteaching', 'Skills of giving effective feedback', 'Objective Structured Clinical Examination/Objective structured Practical Examination' and 'Question paper setting' as very important. $58.8 \%$ of participants self-rated 'Taxonomy' as less important. Among the skills acquired during the program $76 \%$ of participants rated 'Microteaching', 'Appropriate use of Media in Medical Education', 'OSCE' and 'Teaching Learning methods' as the topics through which they learnt the skills which were significant statistically.

Conclusions: The participants recognized their existing teaching skills and how these workshops can effectively mould them into good teachers. Retrospective pre/post ratings may provide a more sensitive and more valid measure of the effects of faculty development programmes on the individuals.

Key words: Faculty Development Programme

\section{Introduction}

Faculty Development Programmes (FDPs) are becoming popular in India. FDPs have gained immense significance in developing the responsibilities of medical educators as a teacher, trainer, clinician, researcher, administrator \& medical education leader. The major part of FDPs includes workshops, seminars, short courses \& longitudinal programmes (Bligh et al., 2009).

${ }^{1}$ Department of Physiology, Meenakshi Medical College Hospital and Research Institute,

Enathur, Kanchipuram, India

${ }^{2}$ Department of Physiology, ESIC Medical College, KK Nagar, Chennai, India

Corresponding Author:

Dr. M. Revathi

Department of Physiology

Meenakshi Medical College Hospital and Research Institute, Tamil Nadu, India

Email: revatymk@gmail.com
Faculty Development Programmes form an integral training programme for medical teachers to learn the principles of teaching, learning and assessment to improve the quality of medical education both professionally and personally (McLean et al., 2008).

FDPs in India started with the National Teacher Training Centre (NTTC) at the Jawaharlal Institute of Postgraduate Medical Education \& Research (JIMPER), Pondicherry in 1976. The FDPs are tailored to the needs of the institution, departments \& individuals. These FDPs also provide a systematic approach in their planning, implementation \& evaluation which contribute to the personal \& professional development of the faculty (Adkoli, 2009). The Medical Education Unit (MEU) of Meenakshi Medical College Hospital \& Research Institute (MMCH \& RI) was established in 2007. The objective of conducting FDPs is to enhance the skills of all the faculty members in teaching, assessment \& educational research. It is usually a three day 
workshop as per Medical Council (MCI) of India guidelines and the frequent competencies covered during FDPs are teaching-learning methods, student assessment and appropriate media use in medical education. Group discussions, lectures, demonstrations and role play were the activities frequently used during FDPs to impart knowledge \& skills (Davis, et al., 2005).

The FDPs are evaluated for all the competencies discussed. FDPs evaluation should be linked to the desired outcomes. The FDPs feedback can allow modifications in existing programmes as required. FDPs are usually evaluated with different assessment methods (Farley et al., 2008). The FDP evaluation has four hierarchical levels; Reaction, Learning, Behaviour and Results. The feedback questionnaires \& pre-test, posttest are commonly used to assess the reaction towards and knowledge gained in the FDPs. However the latest retrospective pre-test \& post-test evaluation is useful for one time short duration workshops (McLeod et al., 2003; Skeff et al., 1992; Davis, 2003). Retrospective pretest post-test evaluations provide an accurate assessment of programme outcomes than traditional pre-test post-test assessments. Retrospective pre-evaluations are useful for documenting self-assessment changes in both importance and skills learned (McLeod et al., 2008; Robert, 2011). The retro pre method of assessment allows participants to rate their perception regarding their knowledge and skills after and before the workshop.

This method has 14 items on a scale of 1-5 for indicating participants' perceptions on knowledge and skills. In our institute we have been conducting FDPs for in house faculty annually for the past three years. At the end of each day, the day's session is evaluated with a questionnaire and retrospective and pre evaluation which is self-administered by the participants. Gregory (2003) mentioned that a retrospective pre evaluation questionnaire gives an immediate impact of the workshop but it can also be used for assessing the intermediate and long-term outcomes of the programmes. According to $\mathrm{MCl}$ guidelines, faculties should undergo training in the Basic Course workshop in Medical Education Technology as a criterion for academic promotion.

\section{Aim of the study}

1. To evaluate the perception of participants on the importance of various topics in FDP before and after attending the workshop
2. To analyse the participants' perception on the skills learnt in the FDP before and after attending the workshop

\section{Methodology}

A 3 day FDP has been conducted annually for the past three years at MEU of $\mathrm{MMCH} \& \mathrm{RI}$ as per $\mathrm{MCl}$ guidelines in the presence of a $\mathrm{MCl}$ observer. Every year, the total numbers of participants were limited to 20-25 in-house faculty from various clinical and nonclinical departments. A total of 62 faculty members have attended the workshop over the past three years. The faculty comprised of all levels from Professor, Associate Professor to Assistant Professor. The retrospective pre-evaluation questionnaire was handed to all the participants during registration which was recommended by the Medical Council of India.

At the end of each day participants were asked to complete the retrospective pre-evaluation questionnaire for the various competencies covered. The retrospective pre-evaluation questionnaire had two components: perceived importance of the various competencies before the discussion and after the discussion in the 3 days' workshop. This was self-rated by the participants. The other component was the perceived skill rating before and after the 3 day workshop. Approximately 14 competencies were self-rated by participants. The importance of the competencies was rated on a Likert scale of 1-5: 1-not important, 2-less important, 3slightly important, and 4-Moderately important and 5- very important. The skills perceived were rated on a scale of 1-5: 1-not at all, 2-slightly skilled, 3-somewhat skilled, 4-moderately skilled and 5-highly skilled. The retrospective pre evaluation questionnaire of the previous 3 years $(2012,2013$, and 2014) was analysed statistically by using the paired t test.

\section{Results}

The three day Basic Course workshop has been conducted by the MEU at $\mathrm{MMCH} \& \mathrm{RI}$ regularly for the past three years. The participants were in-house faculty consisting of 62 members from all levels. There were 4 (6\%) Professors, 3 (5\%) Associate Professors and the remaining 55 (89\%) were Assistant Professors. At the end of each day the retrospective pre evaluation questionnaire was self-rated by the participants according to a 5 point Likert scale. The self-ratings of the retrospective pre-evaluation questionnaire for perceived importance of the competencies before and after the workshop are shown in Table 1. 
Table 1: Observation of self-ratings of perceived importance of various competencies before and after workshop

\begin{tabular}{lcc}
\hline \multicolumn{1}{c}{ Topics } & $\begin{array}{c}\text { Perceived Importance before } \\
\text { workshop (interquartile range) }\end{array}$ & $\begin{array}{c}\text { Perceived Importance after } \\
\text { workshop (interquartile range) }\end{array}$ \\
\hline Group Dynamics & 1.75 & 4.2 \\
System Approach & 1.4 & 4 \\
Learning Process & 1.95 & 4.1 \\
Adult Learning & 1.6 & 3.65 \\
Taxonomy of learning & 1.75 & 3.65 \\
Specific Learning Objectives & 1.6 & 4 \\
Appropriate use of Media & 2.8 & 4.65 \\
Microteaching & 2.25 & 4.45 \\
Curriculum development & 1.4 & 3.6 \\
Principles of assessment & 1.6 & 4.05 \\
Essay & 2 & 4.3 \\
Question paper setting & 2.25 & 4.3 \\
MCQ & 1.9 & 4.4 \\
Feedback & 1.4 & 4.25 \\
Internal Assessment & 1.5 & 4.25 \\
E-learning & 2.35 & 4.2 \\
Teaching methods & 2.4 & 4.3 \\
Bedside teaching & 2.65 & 4.35 \\
Foundation course & 1.5 & 4 \\
Oral exam & 2.2 & 4.25 \\
Long case examination & 2.15 & 4.05 \\
OSCE/OSPE & 2.05 & 4.35 \\
\hline
\end{tabular}

Figure 1: Participants' rating on the importance of the individual sessions before and after the workshop using retrospective pre-evaluation questionnaire on a rating scale of 1-5, where 1-not important and 5-very important

The importance of all the topics was statically significant with $P<0.0001$ when comparing the ratings before and after the workshop.

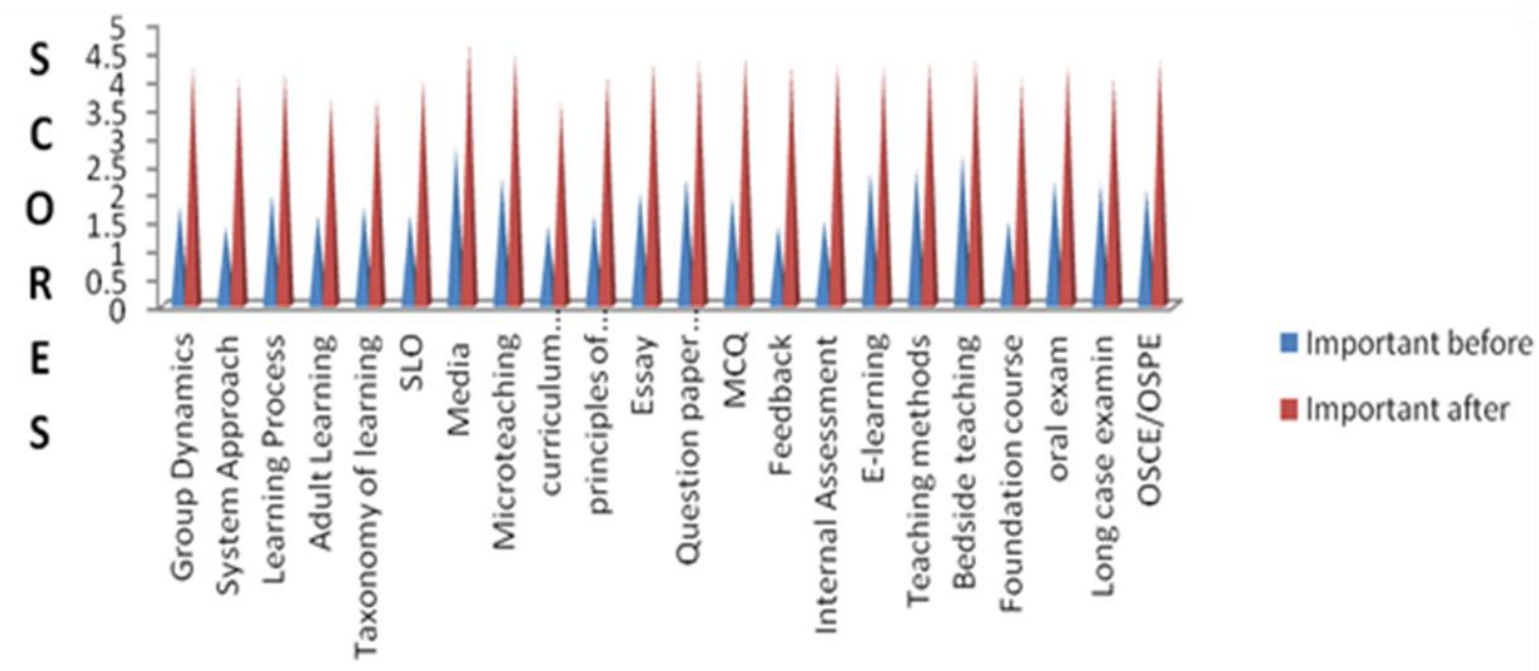

SESSION TOPICS 
All participants stated that they completely benefitted from this workshop. 94\% of the participants self-rated the importance of the competencies, which was highest for 'Microteaching' (87\%),followed by 'Setting up of question paper', 'Assessment', 'Skills of feedback' (82.5\%), 'Interactive teaching learning methods' (75\%), 'Appropriate use of media' and 'Assessment of knowledge' (70\%). The participants also rated the following as least important; 'Taxonomy of learning' (18\%),
'System approach', 'Adult learning' (45\%), 'Learning process \& curricular innovations' (57.5\%). The results are shown in Table 1 and Figure 1. The skills achieved after the completion of the workshop were as follows: 'Microteaching', 'Clinical \& practical assessment' (76\%), 'Appropriate use of media' $(65.7 \%)$ and 'Teaching learning methods' $(60 \%)$ which are represented in Table 2 and Figure 2.

Table 2: Self-rating of retro pre-evaluation questionnaire for the skills Acquired before and after completion of the workshop

\begin{tabular}{lcc}
\hline \multicolumn{1}{c}{ Topics } & $\begin{array}{c}\text { Skills perceived before } \\
\text { workshop (interquartile range) }\end{array}$ & $\begin{array}{c}\text { Skills perceived after } \\
\text { workshop (interquartile range) }\end{array}$ \\
\hline Group Dynamics & 1.9 & 3.95 \\
System Approach & 1.55 & 3.65 \\
Learning Process & 2.05 & 3.75 \\
Adult Learning & 1.8 & 3.9 \\
Taxonomy of learning & 1.8 & 4.05 \\
Specific Learning Objectives & 1.45 & 3.95 \\
Appropriate use of Media & 2.25 & 4.25 \\
Microteaching & 2 & 4.45 \\
Curriculum development & 1.25 & 3.5 \\
Principles of assessment & 1.7 & 3.7 \\
Essay & 1.7 & 3.8 \\
Question paper setting & 2.15 & 4.05 \\
MCQ & 2 & 4.1 \\
Feedback & 1.75 & 4.2 \\
Internal Assessment & 1.45 & 3.85 \\
E-learning & 2 & 3.9 \\
Teaching methods & 1.85 & 4 \\
Bedside teaching & 2.1 & 4.1 \\
Foundation course & 1.6 & 3.85 \\
Oral exam & 2.05 & 4.05 \\
Long case examination & 2.3 & 4 \\
OSCE/OSPE & 1.95 & 4.1 \\
\hline
\end{tabular}

Figure 2: Participants' perceived self-rated skills before and after the workshop

The results were highly significant $(p<0.0001)$ after the workshop for the skills learned in the various topics.

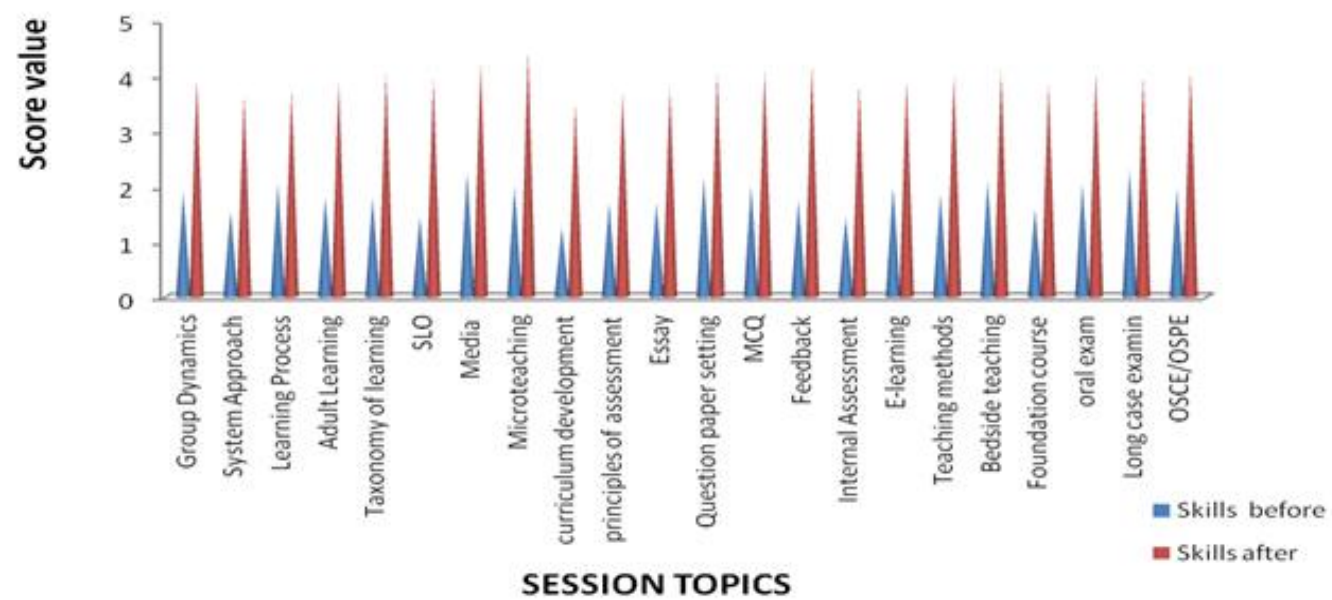




\section{Discussion}

This study was the analysis of the self-rated retrospective pre-evaluation questionnaire collected from all the participants of the three day Basic Course workshop, conducted at the Meenakshi Medical College Hospital \& Research Institute. About 100 faculty members of the $\mathrm{MMCH} \& \mathrm{RI}$ participated. A high number of Assistant and Associate Professors participated in the workshops. This may be due to the academic regulations for promotions by the Medical Council of India. A total of 14 topics (competencies) were included in the questionnaire sent by the Medical Council India for evaluation of the FDP workshop. The overall mean in relation to the importance of the 14 topics increased from 2.8 (before) to 4.3 (after), while the mean in relation to skills gained, increased from 2.3 (before) to 4 (after). The topics prioritized by the participants were microteaching, OSCE/ OSPE, feedback skills, appropriate use of media, both in importance and skills. This prioritization may be due to the experience level of participants who were mostly junior faculty mainly at the Assistant Professor level, who had very limited teaching experience.

The remaining topics such as curriculum innovation, e-learning in media, appeared to sensitize the participants, who will require more workshops on such topics, to achieve the skills for the next level of workshops in Medical Education Technologies. The prioritizing of the topics both in importance and skills can be due to the regular involvement of participants in these activities academically as they were involved with skills training like practical demonstrations than Professors (Hewson et al., 2001). The topics can be tailored for different experience levels of faculties (McLean et al., 2008). The new faculties can be sensitized to these topics with orientation programmes followed by advanced workshops (Steinert, 2000). The participants suggested other topics like research methodology, paper publication and medical ethics to be included in the FDP workshop (Adkoli, et al., 2010). Overall, participants experienced a positive change in the importance of the competencies and the skills learnt from the workshop (Steinert et al., 2006; Ozlem, 2010). With an interdisciplinary perspective the FDPs will have a great impact (Gelula et al., 2002). The ability of the participants to apply this knowledge in their respective department can be assessed by a short project (Sommers et al., 2000). Currently the $\mathrm{MCl}$ has made mandatory that all FDPs are completed with a short project presented by the participants.

\section{Conclusion}

All the medical faculties have to undergo the $\mathrm{MCl}$ recognised three days Basic Course workshop in Medical Education. The workshop is evaluated by the $\mathrm{MCl}$ provided retrospective pre-evaluation questionnaires. The participants self-rated the competencies in both importance and skills achieved before and after the workshop. The participants suggested additional topics to be included in the workshop and that it be organised for different levels of faculty. We conclude that in the FDP 'Microteaching', 'Practical \& clinical skill assessment', 'Appropriate use of media' and 'Question paper setting' were considered important and most useful in terms of learning skills. The reason these topics were chosen as important may be due to the higher perceived relevance of teaching and assessment of students in day to day medical education. Our participants realized their current levels of teaching skills and how these types of workshops can effectively mold them into good teachers.

\section{References}

Adkoli, B.V., Al-Umran, K.U., Al-Sheikh, M.H. \& Deepak, K.K. (2010) Innovative Method of Needs Assessment for Faculty Development Programs in a Gulf Medical School, Education for Health, 23, 3, p. 389.

Adkoli, B.V. \& Sood, R. (2009) Faculty development and medical education units in India: A survey, National Medical Journal of India, 22, pp. 28-32.

Bligh, J. \& Brice, J. (2009) Further insights in to the role of medical educator, Academic Medicine, 84, pp.1161-1165.

Davis, M., Karunathilake, I. \& Harden, R.M. (2005) AMEE Education Guide no. 28: The development and role of departments of medical education, Medical Teacher, 27, pp. 665-675.

Davis, G. (2003) Using a retrospective pre-post questionnaire to determine program impact, Journal of Extension [Online] 41, 4, Article 4TOT4, Available at: http://www.joe.org/joe/2003august /tt4.php.

Farley, H., Caseletto, J., Ankel, F., Young, K.D. \& Hockberger, R. (2008) An assessment of the Faculty Development needs of junior clinical faculty in Emergency Medicine, Academic Emergency Medicine, 15, pp. 664-668.

Gelula, M. \& Yudkowsky, R. (2002) Microteaching and standardized students support faculty development for clinical teaching, Academic Medicine, 77, p. 941. 
McLean, M., Cilliers, F. \& Van Wyk, J.M. (2008) AMEE Guide No. 36: Faculty Development: Yesterday, today and tomorrow, Medical Teacher, 30, pp. 555-584.

McLeod, P.J., Steinert, Y., Meagher, T. \& McLeod, A. (2003) The ABCs of pedagogy for clinical teachers, Medical Education, 37, pp. 638-644.

McLeod, P.J., Yvonne \& Snell, L. (2008) Use of retrospective pre / post assessments in faculty development, Medical Education, 42, pp. 513543.

Nielsen, B.R.(2011)A Retrospective Pretest-Posttest Evaluation of a One-Time Personal Finance Training, Journal of Extension [Online], 49, 1, Available at: $\quad w w w . j o e . o r g / j o e / 2011$ February/a4.php.

Ozlem, S. (2010) The impact of a faculty development program: evaluation based on the self-assessment of medical educators from preclinical and clinical disciplines, Advances in Physiology Education, 34, pp. 35-40.
Skeff, K. M., Bergen, M. R., \& Stratos, G. A. (1992) Evaluation of a medical faculty development program: A comparison of traditional pre/post and retrospective pre/post self-assessment ratings, Evaluation and the Health Care Professions, 15, 3, pp. 350-366.

Sommers, P.S., Muller, J.H. \& Ozer, E.M. (2000) The faculty self-efficacy scale: A tool for evaluating faculty development interventions, Academic Medicine, 75, pp. 559-560.

Steinert, Y. (2000) Faculty development in the new millennium: key challenges and future directions, Medical Teacher, 22, pp. 44-50.

Steinert, Y., Mann, K., Centeno, A., Dolmans, D., Spencer, J. \& Gelula M. (2006) A systematic review of faculty development initiatives designed to improve teaching effectiveness in medical education: BEME Guide No. 8, Medical Teacher, 8, pp. 497-526. 